\title{
Life History of Paracantha gentilis (Diptera: Tephritidae)
}

\author{
DAVID HEADRICK AND RICHARD D. GOEDEN
}

Department of Entomology, University of California, Riverside, California 92521

\begin{abstract}
Ann. Entomol. Soc. Am. 83(4): 776-785 (1990)
ABSTRACT The life history of Paracantha gentilis Hering in southern California is described. This stenophagous tephritid reproduces in the capitula of native Cirsium thistles. Courtship and mating behavior are described from field and laboratory observations. Territorial and courtship behavior of males and the morphological characters involved in possible male pheromone emission are described and illustrated, as are the oviposition behavior and reproductive morphology of females. Egg clutch sizes ranged from one to 13 eggs, with a maximum of six clutches per capitulum. Larvae fed gregariously within stage-specific niches. Pupariation occurred in the capitula, from which adults emerged in mid-June through early July. After emergence, most adults probably disperse to higher elevations to feed until autumn, then return to lower elevations and reproduce the following year. Limited reproduction also occurs in late-formed capitula or in capitula of alternate Cirsium hosts.
\end{abstract}

KEY WORDS Insecta, Paracantha gentilis, Cirsium, life history

Paracantha gentilis Hering (1940) is found throughout the western United States and northern Mexico and is the most common of the three species in this genus in California (Foote \& Blanc 1963). The host plants of $P$. gentilis are thistles in the genus Cirsium (Asteraceae) (Foote \& Blanc 1963; Pemberton et al. 1985; Goeden \& Ricker 1986a,b, $1987 \mathrm{a}, \mathrm{b})$. In southern California, $P$. gentilis infests capitula of eight native and one introduced species of Cirsium, the two most common being C. californicum Gray and C. proteanum J. T. Howell (Goeden \& Ricker 1986b). Paracantha gentilis Malloch has been reared from crowns of rosettes of C. californicum, C. congdonii Moore and Frankton, C. cymosum (Greene) J. T. Howell, and C. vulgare (Savi) Tenore (Pemberton et al. 1985; Goeden \& Ricker 1986a,b); whereas P. cultaris (Coquillett), the third species in California, attacks only Helianthus spp. (Cavender \& Goeden 1984).

Our study of the life history of $P$. gentilis was an outgrowth of faunistic surveys of C. californicum and C. proteanum (Goeden \& Ricker 1986b), in which $P$. gentilis was found to be part of a small guild of insects infesting the capitula.

\section{Materials and Methods}

Study sites in the spring and summer of 19871988 were located at Mill Creek and Upper Fish Creek Meadow, San Bernardino National Forest, San Bernardino Co., Calif., and at Sawmill Mt., Angeles National Forest, Los Angeles Co., Calif. C. californicum and C. proteanum grow in patchy aggregations along roads and hillsides in the foothills of southern California above $1,000 \mathrm{~m}$. At the Mill Creek site, three patches of $C$. californicum plants were inspected 3-5 d each week, and 1025 capitula were collected weekly for dissection to determine the feeding behavior and resource allocation of larvae. Behavior of adults in the field was monitored during each visit. Puparia dissected from capitula were placed individually in separate 60 -ml plastic vials fitted at one end with 100 -mesh brass screening for ventilation and held at $26 \pm$ $1^{\circ} \mathrm{C}, 30-60 \% \mathrm{RH}$, and a photoperiod of 12:12 (L:D) in the insectary of the Department of Entomology, University of California, Riverside. Newly emerged virgin adults were paired and held in $850-\mathrm{ml}$ plastic, ventilated cages furnished with water and honey to observe courtship behavior. Inseminated females were taken to the Mill Creek site in ice chests by air-conditioned van for sleeve-caging on capitula to study oviposition behavior.

Studies of female reproductive anatomy were carried out on specimens fixed in $70 \% \mathrm{EtOH}$ and dissected in alcohol with $0.1 \%$ acid fuchsin. The abdomens of mature females were dissected to determine how the large, elongate eggs (described by Headrick \& Goeden 1990) are accommodated internally. The heads of four adult males were fixed in Carnoy-Lebrun solution for $\mathrm{l} \mathrm{h}$ and stored in $70 \% \mathrm{EtOH}$. Three of the heads were serially dehydrated through graded alcohols to $100 \% \mathrm{EtOH}$ and embedded in a plastic mounting medium. These plastic blocks were sectioned using a JB-4 ultramicrotome set at $3 \mu$. Serial sections were obtained by placing contact cement on the underside of the block. The sections were mounted on slides, stained with toluidine blue, a multi-chromatic, onestep tissue stain, and permanently mounted in Permount (Fisher Scientific, Fairlawn, N.J.). The remaining head was critically point-dried, sputtercoated with a gold-platinum alloy, and studied with a JOEL-JSM-35C3 scanning electron microscope. Specimens were examined, and micrographs were prepared at $15 \mathrm{kV}$ accelerating voltage with 

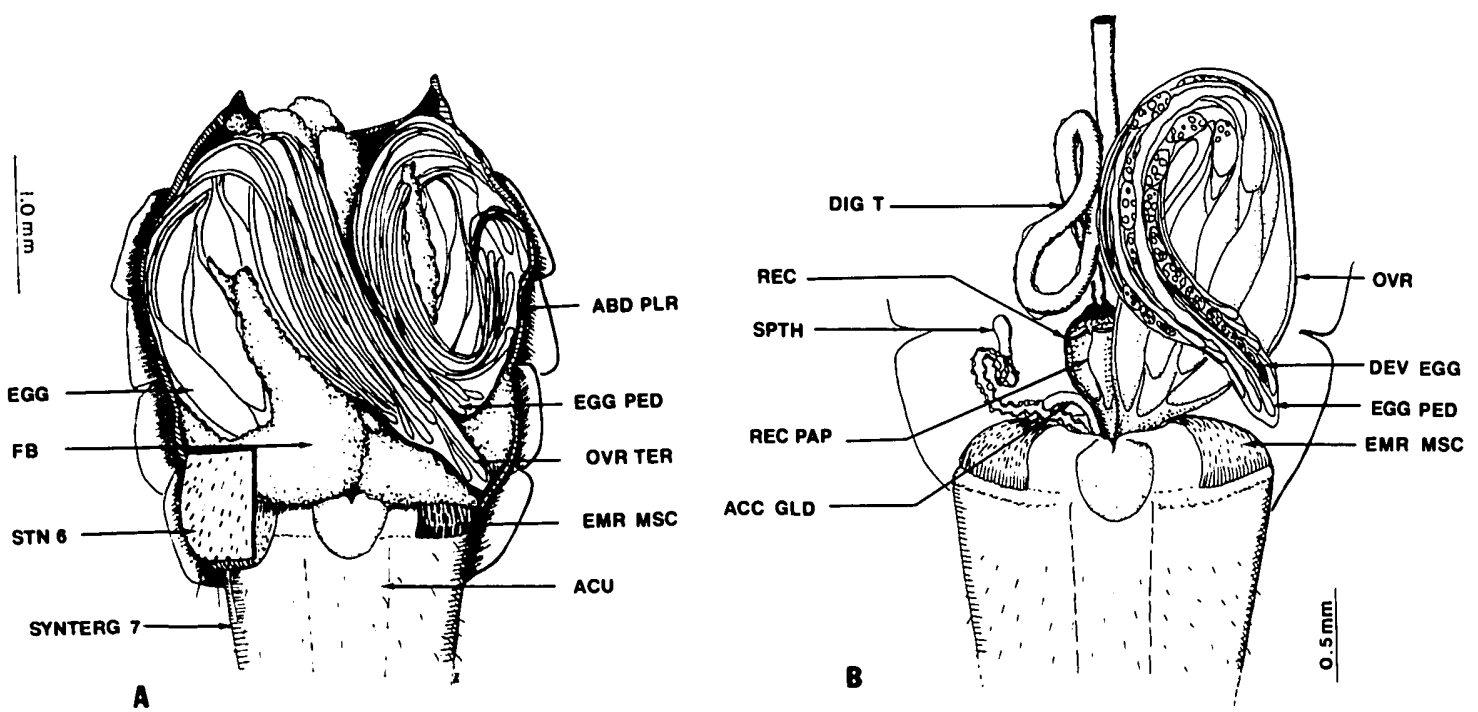

Fig. 1. (A) Ventral view of female abdomen with sterna removed. ABD PLR, abdominal pleura; ACU, aculeus; EGG, egg; EGG PED, egg pedicel; FB, fat body; OVR TER, ovary terminus; STN 6 sternum 6; SYNTERG 7, syntergosternite 7. (B) Ventral view of female abdomen showing placement of internal organs. ACC GLD, accessory gland; DEV EGG, developing egg; DIG T, digestive tract; EGG PED, egg pedicel; EMR MSC, eversible membrane retractor muscle; OVR, ovary; REC, rectum; REC PAP, rectal papilla; SPTH, spermathaeca.

Polaroid $55 \mathrm{P} / \mathrm{N}$ film. The negatives are stored with Gordon Gordh, Department of Entomology, University of California, Riverside. Voucher specimens are stored in the research collection of R.D.G. Means and standard errors are reported throughout.

\section{Results and Discussion}

Phenology. C. californicum and C. proteanum are biennials that form rosettes one year and bolt and flower the next (Munz 1974). Terminal capitula began to appear in the centers of the rosettes of C. californicum from late February to early March at the Mill Creek site. As the single central stems elongate, the surrounding apical leaves unfold and expose the small, immature terminal capitula into which $P$. gentilis females first oviposit. Lateral capitula first appear about 2 wk later, and new lateral capitula are subsequently produced on elongate peduncles basipetally, along with axillary capitula, that do not have elongate peduncles. The terminal capitulum matures and blooms first, followed by the lateral capitula. Anthesis occurs in late May and early June, after which the floral tubes shrivel and dry, the bracts close, and the achenes ripen. The capitula remain on the plant and continue to mature for about $4 \mathrm{wk}$, after which the bracts open once again and the achenes are shed.

Eggs. Females of $P$. gentilis are synovigenic and begin to oviposit about $2 \mathrm{wk}$ after emergence. The egg bodies lie closely packed near the lumen of the oviduct with the long pedicels extending into the terminal portion of the ovary, which lies folded over ventrally to accommodate the full length of the eggs within the abdomen (Fig. 1).

Females laid eggs in uninfested immature capitula as well as in those that already contained $P$. gentilis eggs or larvae. The body of the egg usually was placed lengthwise and parallel to and between the immature floral tubes above the level of the ovules. Average clutch size was $4 \pm 0.4(n=40$; range, 1-13) eggs. A maximum of six clutches (3 \pm 0.3 ) was found in 20 capitula. Eggs were dissected from capitula collected from the field from mid-March to early May. Serial dissections of capitula collected daily for $2 \mathrm{wk}$ indicated that eclosion occurred about 7-10 d after oviposition.

Embryo development was observed through the chorion of 10 eggs dissected from capitula just after oviposition and placed on moist filter paper in covered Petri dishes at $27^{\circ} \mathrm{C}$. Within $48 \mathrm{~h}$ after egg deposition, the cephalopharyngeal skeleton darkened. Eclosion lasted about $5 \mathrm{~h}$ and began with the embryo scraping its mouth hooks into the chorion near the end opposite the pedicel. The chorion split longitudinally, and the larva emerged aided by peristaltic constrictions of its body and by gripping the substrate with its mouth hooks. Emergence of the larvae lasted $10-15 \min (n=5)$.

First Instar. Two to $4 \mathrm{wk}$ after the initiation of oviposition in mid-March, 20 capitula contained $3.0 \pm 0.6$ (range, 1-7) first instars. Each newly eclosed larva tunnelled into a separate floral tube and fed inside for the duration of the first stadium (4-6 d in excised capitula in the laboratory).

Second Instar. Four weeks after initiation of oviposition, 20 capitula contained $2.0 \pm 0.3$ (range, 
1-4) second instars. Eggs and first and second instars shared individual capitula. No other insect species infested the capitula at the Mill Creek site until anthesis, by which time the larvae had reached the third instar or had pupariated. The duration of the second stadium was not determined in the laboratory; however, capitula collected at Mill Creek contained second instars for 3 consecutive wk in 1988.

Third Instar. Third instars tunnel inward from ovules on the outer margins to the center of the capitulum, where they feed on the ovules, sometimes scoring the receptacle, and pupariate in the cavity created by their feeding (unpublished data). The number of puparia in capitula was used to estimate the percentage of larvae successfully completing development. The average number of puparia dissected from 76 infested, mature C. californicum capitula was $3.3 \pm 0.3$ per capitulum (range, 1-12).

Puparium. Pupariation begins when $P$. gentilis larvae stop feeding and turn upward away from the receptacle. Larvae normally pupariate centrally in capitula surrounded by a hard, thick layer of dried and darkened, partially consumed florets. Puparia were present in the field at Mill Creek for $38 \mathrm{~d}$ in 1988.

Adult. Sequential photographs of the emergence of an adult male from a puparium are presented in Fig. 2. Adults began to emerge by expanding their ptilinum and using it to burst the thin pupal exuviae and simultaneously the "cephalic" cap. When the emerging fly broke the cap, the upper three segments of the puparium were opened. The puparium is normally situated with its anterior end directed away from (its long axis perpendicular to) the receptacle. Once the puparium opens, the emerging adult uses its ptilinum to push apart the dried florets and exit the capitulum. The callow adult walks to the nearest shaded part of the capitulum or pedicel, evacuates a drop of dark liquid metabolic waste, and rests. After about $0.5 \mathrm{~h}$, the integument darkens and the adult becomes mobile and grooms itself constantly.

Overwintered adults of $P$. gentilis appeared in the field as early as March at Mill Creek. Adults were most numerous during late March through early May, then declined in numbers until June, when (for about $3 \mathrm{wk}$ ) none was observed in the field. After this absence, adults were observed emerging from the postblossom capitula. Daily observations revealed no more than one or two adults. Previously, adults were collected in late July and August by R.D.G. and D. W. Ricker in Upper Fish Creek Meadow on San Gorgonio Mountain, well above the Mill Creek site. C. californicum and C. proteanum were not present at this high-elevation site $(2,800 \mathrm{~m})$; only C. tioganum (Congdon) Petrak was present, which apparently is not a host of $P$. gentilis (Goeden \& Ricker 1987a).

Adults were swept from nonhost Asteraceae in bloom at Fish Creek Meadow in midsummer in early July 1987. Six hours of sweeping yielded only two females and one male. Dissection of the females revealed that they were either sexually immature or reproductively inactive; i.e., the ovaries contained no full-sized ova. This suggested that these adults did not represent an established reproducing local population but rather, we suspect, had emerged earlier in the season from thistles like C. californicum at lower elevations such as the Mill Creek site. After emergence, adults apparently migrate upward via water courses to pass the summer in cooler, high-elevation meadows. Like some other stenophagous southern California Tephritidae (e.g., Trupanea conjuncta (Adams) [Goeden 1987] and Trupanea imperfecta (Coquillett) [Goeden 1988]), the adults probably return to lower elevations to overwinter from late September to February, at which time they mate and begin to oviposit in thistles flowering in early March.

Five of the 15 females, sleeve-caged separately on individual, immature, lateral capitula, laid a total of nine eggs in these capitula. This, plus the observation of a lone, apparently newly eclosed female ovipositing into capitula $3 \mathrm{wk}$ after the disappearance of the overwintered adults from the field, suggested that a partial second generation may occur at lower elevations where lateral heads are produced by C. californicum and C. protean$u m$ well into the summer. However, dissections of overwintering capitula consistently showed that all adults emerged before the onset of winter; only parasitoids overwintered in puparia that were still intact (Headrick \& Goeden 1989). P. gentilis also uses some less common species of mainly summerblooming Cirsium thistles (i.e., C. mohavense (Green) Petrak and C. nidulum (Jones) Petrak) as alternate hosts on a limited basis (Goeden \& Ricker 1987b).

Adult Behavior. On thistles, $P$. gentilis adults generally walk slowly and smoothly and do not readily fly to other plant species. The rostra of both sexes of $P$. gentilis pump continuously, as reported for P. cultaris by Cavender \& Goeden (1984). Associated with the pumping of mouthparts was the extrusion of a clear, golden drop of liquid while the adults rested. The droplet grew in size with each pump until it reached the size of the head. After a few seconds, it was imbibed rapidly, and the process was repeated.

Another common activity of $P$. gentilis was wing extension. Wing extension has been reported as "flicking," "waving," or "fanning" as part of the precourtship, courtship, and agonistic behavior of many tephritids and may serve as a cue for species recognition (Zwölfer 1974).

Wing extension in $P$. gentilis was exhibited by both sexes and is described first in terms of the general actions involved. The wing was brought forward to a point perpendicular to the thorax, broad undersurface facing forward, costal end upward (Fig. 3) (i.e., supination). Wing extension by an individual was synchronous (i.e., both wings 


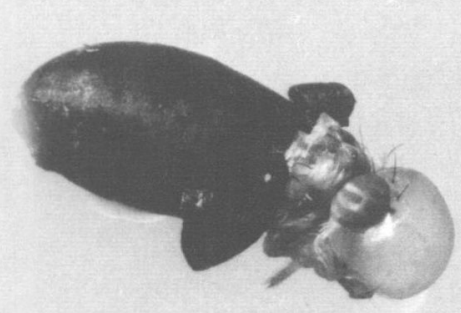

A
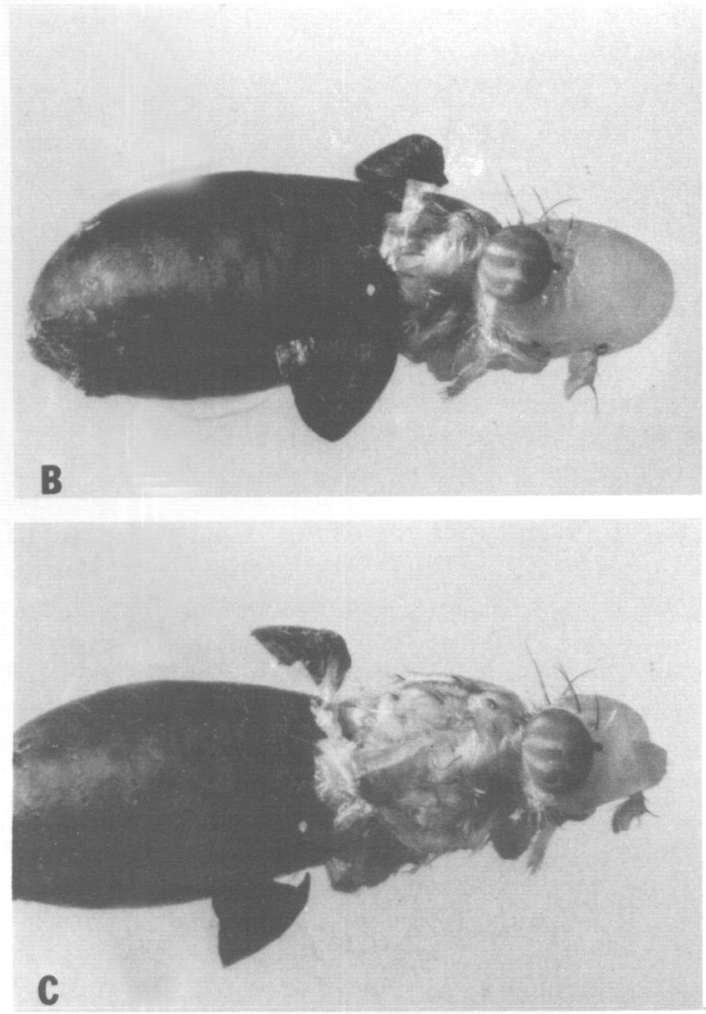
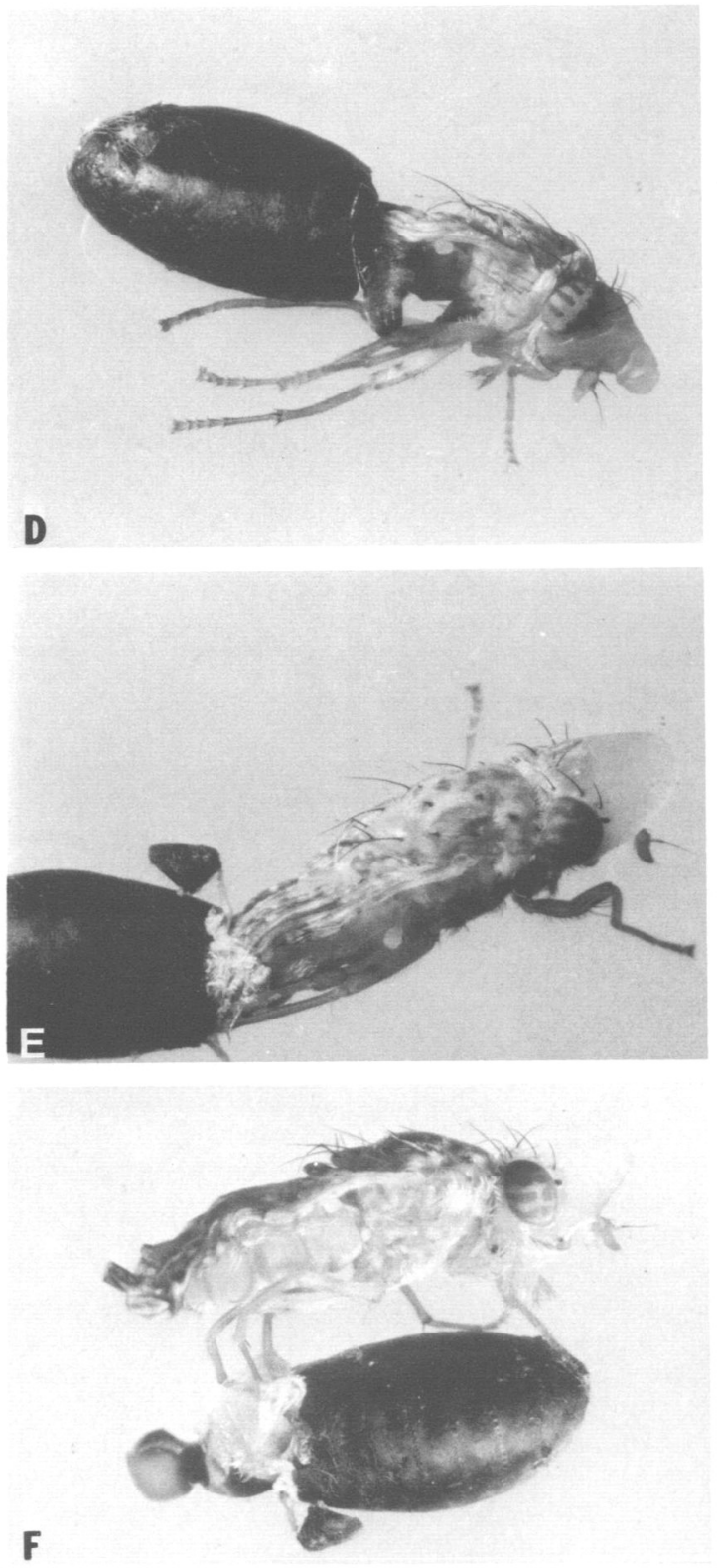

$\mathbf{F}$

Fig. 2. Photographic sequence of adult emergence. Elapsed times from (A) $t=0,(B) 5 \mathrm{~min},(C) 45 \mathrm{~min}$, (D) $90 \mathrm{~min},(\mathrm{E}) 120 \mathrm{~min},(\mathrm{~F}) 150 \mathrm{~min}$.

were brought forward together to a point where they form a straight line roughly perpendicular to the long axis of the body), or asynchronous (i.e., one wing was brought forward while the other was held tlat over the dorsum, and then the extended wing was returned and held flat over the dorsum, while the other wing was extended). The wings occasionally were vibrated rapidly as they were brought forward. Wing extension also has been described in several other Tephritidae; e.g., Tauber
\& Toschi (1965a,b), Pritchard (1967), Prokopy \& Bush (1973), Piper (1976), Berube (1978), Batra (1979), Prokopy \& Hendrichs (1979), Cavender \& Goeden (1983, 1984), and Goeden et al. (1987). The rapidity of wing extension was variable and corresponded to the associated behavior; i.e., fast extension during apparently agonistic behavior. Wing extension while the fly explored or rested started slowly and asynchronously, about one extension per 2-5 $\mathrm{s}$, with pauses between extensions 


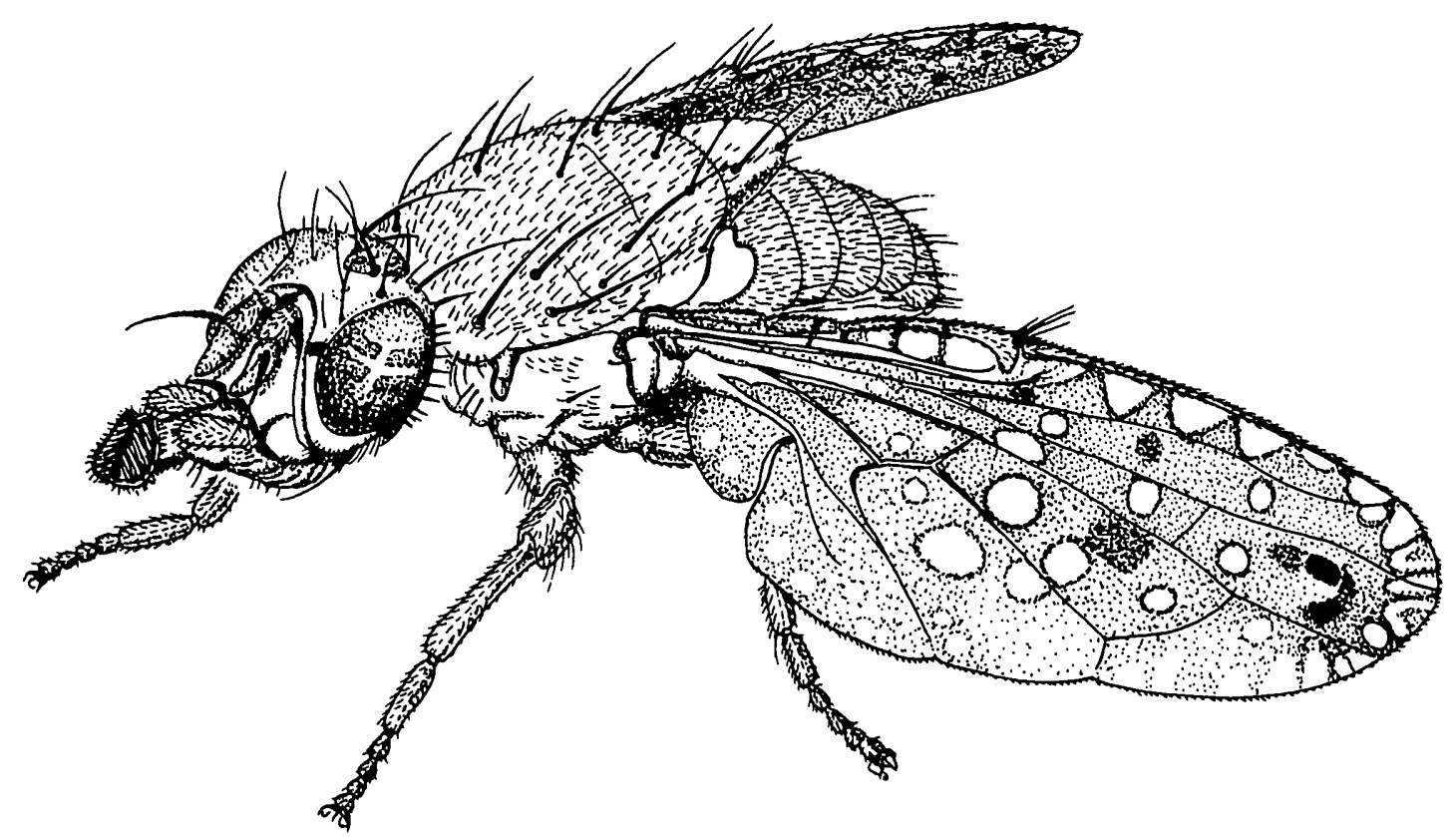

Fig. 3. Male wing display.

of 3-5 s. When flies showed apparent agonistic behavior, their wing extensions became rapid and synchronous.

Audible wing vibrations were heard during agonistic behavior by both sexes and during male territoriality contests. When this occurred, the wings were held over the dorsum. Webb et al. (1976) analyzed and identified wing sounds peculiar to specific types of behavior in the Caribbean fruit fly, Anastrepha suspensa (Loew), including aggression and courtship.

Host Finding. Males and females of $P$. gentilis use thistles for shelter, food, reproduction, and oviposition. Adults fly to the thistles from unknown sources after about 0900 hours (PDST). Females arrive first and generally fly to the lower leaves. They rest, groom, and move between shady and sunny locations for varying periods. Exploration of the plants by females begins about 1000 hours as they walk up the stem to the next higher leaf. After walking out on this leaf, they return to the stem and again move upward. If an axillary bud is encountered by the female, she usually probes it with her ovipositor. The female eventually reaches an elongated peduncle and walks onto a young capitulum to begin oviposition.

Males, on the other hand, fly to the lower leaves of the thistles slightly later, starting at about 1000 hours. They rest, groom, and move from sunlit areas to shade for varying periods.

The number of flies observed on a single thistle plant varied from one to nine during peak activity between 1000 and 1500 hours. Once on a thistle, the flies usually walk or make short jumps between a leaf or stem. The time spent on a single plant varied from about $1 \mathrm{~min}$ to a maximum of $5 \mathrm{~h}$. When ready to leave a plant, a fly visually orients to a different thistle nearby. Visual orientation to a new host individual was described for Euaresta bella Loew by Batra (1979). Facing the newly located plant, the $P$. gentilis adult raises its upper body on its extended forelegs and jumps to initiate flight. This "jump-fly" take-off behavior was reported for Neotephritis finalis (Loew) by Goeden et al. (1987).

Feeding. Males and females commonly feed on sap at the oviposition wounds in C. californicum capitula. This apparently common practice among tephritids is best documented for frugivorous species (Christenson \& Foote 1960). Adults of $P$. gentilis were not observed feeding on inflorescences of other species in bloom in our study sites. Feeding lasted $5-30 \mathrm{~min}(14 \pm 2.2 \mathrm{~min}, n=15)$. Other insects, mostly ants, also feed at these oviposition punctures. $P$. gentilis adults defended wounds at which they fed against other insects (e.g., ants) by lunging at the intruders and audibly buzzing their wings. They never challenge ants feeding on capitula but, rather, continue their search for an unoccupied capitulum. Agonistic behavior of adult tephritids toward other insects in defense of territory or oviposition sites but not in defense of a food source has been reported by other workers; e.g., Tauber \& Toschi (1965a,b), Prokopy \& Bush (1973), Webb et al. (1976), Berube (1978), and Batra (1979).

Courtship and Mating. In early March, two or three males usually were found on each plant, and up to 10 males on four plants in an area 3 by $3 \mathrm{~m}$, 

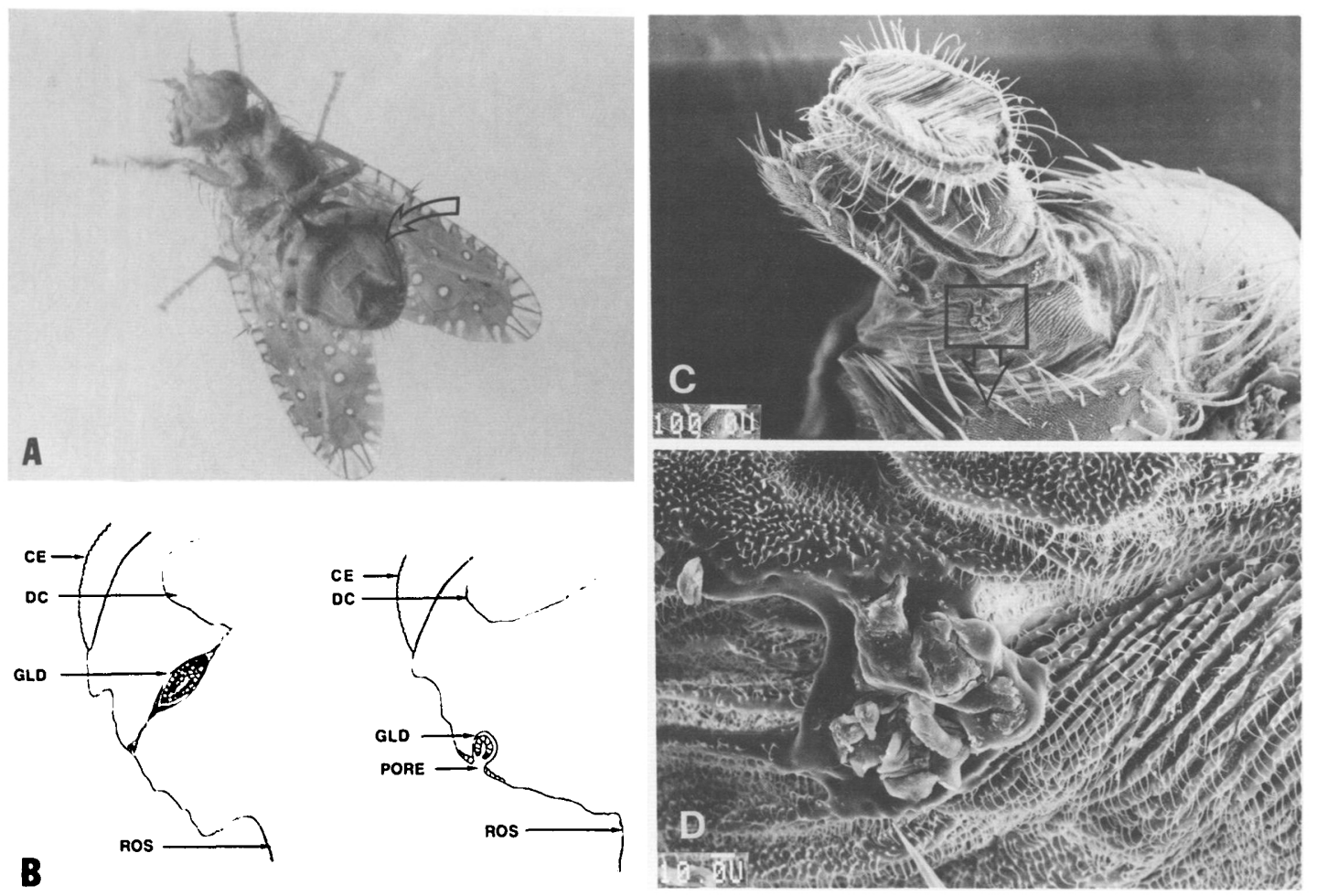

Fig. 4. (A) Male abdominal pleural distention (arrow). (B) Cross-section of the male head (diagrammatic). CE, compound eye; DC, deuterocerebrum; GLD, gland; ROS, rostrum. (C) SEM ventral view of male head with rostrum extended. (D) Detail of gland pore. Note: liquid has issued from the pore.

but the boundaries of a specific male lek could not be defined. Generally, individual male territories are located on lower sunlit leaves of plants on the perimeter of a thistle patch in an open space free of other vegetation. Females, on the other hand, normally explore the upper parts of the thistles for food and oviposition sites.

Territoriality. Territorial displays between tephritid males have been described as "lunging" or "butting" with proboscis and wings extended. Freidberg (1981) described a somewhat more complicated territorial behavior between males of Schistopterum moebiusi Becker. P. gentilis males also display complex territorial behavior.

Defensive territorial behavior begins when a male intrudes upon the established territory of a male and begins asynchronous wing extension. When visual contact is made with the intruder, the established male's normally smooth movements become agitated. He begins walking in tight circles (about $1 \mathrm{~cm}$ diameter) and extends his wings synchronously forward at a rapid rate (about 1-2 times/ s). The intruder responds with the same behavior and walks to within $7 \mathrm{~cm}$ of the established male. Facing each other, they extend their wings forward alternately as each takes a step, repeating this sequence until they are about $1 \mathrm{~cm}$ apart. The rhythm of their wing extensions slows as they move closer to each other. When their heads almost touch, their wing extensions cease, and they rise on their forelegs, extend their mouthparts, and touch labellae. In one instance, they held their labellae together and rotated their heads from side to side through about $90^{\circ}$. The established male audibly buzzed his right wing and vibrated it rapidly back and forth through about $45^{\circ}$ in the same plane in which the wing was held when at rest. This behavior, in turn, was answered and mirrored by the intruder. This sequence of "call-answer" behavior occurred five times, and each sequence lasted about $1 \mathrm{~min}$. In another instance, two other males held their wings crossed over their dorsa while their labellae were pressed together without the call-answer wing extensions.

The intruding male breaks from the established male and is chased away. If the intruding male returns, agonistic behavior resumes. Established males again chase the intruders away but without renewed labellar contact and thus retain their territories. Intruding males fly to nearby thistles and begin displaying (described below). Both of these male territorial encounters lasted about $30 \mathrm{~min}$. Females already in the area did not react to this contest display between males.

Male Display Behavior. Male displays consisted of walking to the upper surface of a leaf, distending 
the sides of the abdomen, and extending the wings synchronously. Males displayed continuously in nature as long as $5 \mathrm{~h}$. The distended pleuron was easily visible and was bright orange (Fig. 4A). This distension of the male pleura has been reported for several species; e.g., Rhagoletis spp. (Christenson \& Foote 1960, Prokopy \& Bush 1973), Dirioxa (Rioxa) pornia (Walker) (Pritchard 1967), Euaresta spp. (Batra 1979), Schistopterum moebiusi (Freidberg 1981), Trupanea bisetosa (Coquillett) (Cavender \& Goeden 1982), and Anastrepha spp. (Nation 1972, da Silva et al. 1985). Pheromone production may be involved as indicated for Anastrepha spp. by da Silva et al. (1985) and for T. bisetosa by Cavender \& Goeden (1982), who reported a distinct "yeasty" odor in cages containing an abundance of males. No such odor was noted with $\boldsymbol{P}$. gentilis males.

Another possible source of pheromone production was revealed by microscopic examination of the male head capsule. A large open space in the ventral portion of the head capsule contains a pair of elongate glands and a pore that opens to the outside (Fig. 4B). This pore was located using SEM and is situated ventrally on the membranous part of the head capsule posterolaterad of the maxillary palpi (Fig. 4C). Further investigation of specimens in alcohol showed the glands and pores are visible with the dissecting microscope, and females lack both. The mouthparts of the male and female are musculated differently, such that the male can greatly extend his mouthparts and balloon the membranous area of the head capsule, thus exposing the pore (Fig. 4D) and possibly emitting a pheromone.

Courtship. Several mating systems have been described for tephritids in the literature. There is no consistency in which sex initiates courtship. Tauber \& Toschi (1965a) reported that either sex of Tephritis stigmatica (Coquillett) made the initial approach. Females of Anastrepha spp. are reported to fly to the leaf of a displaying male (Burk 1983, Morgante et al. 1983); however, Polloni \& da Silva (1986) observed a male Anastrepha sp. that flew to the female. In the field, female $P$. gentilis began exploring the upper parts of the plants before the males began displaying. If a wandering female passes close to a displaying male, he moves toward her and extends his wings. Similar "chance" encounters have been reported by Wangberg (1978), Batra (1979), Cavender \& Goeden (1982, 1983), Dodson (1987), and Goeden et al. (1987) to initiate courtship among other nonfrugivorous tephritids.

When a displaying male of $P$. gentilis makes visual contact with a female, he walks to within 2$3 \mathrm{~cm}$ of her; his abdominal pleura are not distended and remain normal through courtship and mating. If the female is not receptive, she moves away and the male resumes displaying. If not rejected, the male, facing her head-on from either side, extends his wings synchronously. The female usually re- sponds by facing the male. The male then extends his mouthparts, ballooning the ventral membrane such that the ventral surface of the labellum faces upward, and continues extending his wings (Fig. 5). He produces a frothy drop of whitish liquid as wide as the labellum on its upward-facing surface. He vibrates the labellum rapidly, which causes the drop of liquid to vibrate. The female approaches the male, extends her labellum, and places it down on the ball of liquid. They remain with their labellae touching and vibrating for as little as $20 \mathrm{~s}$ but for as long as $20 \mathrm{~min}$. When one pair parted, a string of liquid was seen between their labellae, indicating the frothy droplet was transferred from the male to the female. Similar trophallaxis behavior was reported in another species of Paracantha, P. cultaris (Cavender \& Goeden 1984). These offerings can be quite complex in other tephritids, involving mounds of foam upon which females feed during mating (Pritchard 1967, Batra 1979, Freidberg 1981). P. gentilis couples were easily disturbed and broke away and rejoined several times during premating trophyllaxis; e.g., during one 20min period, a couple separated and rejoined eight times at about 2-min intervals. That premating pairs were "easily disturbed" was reported by Batra (1979), Freidberg (1981), and Cavender \& Goeden (1984).

A $P$. gentilis female could reject a male during trophallaxis by raising her labellum, stepping backward, turning, and walking away. The rejected male often pursues the female for at least a short distance but then abandons pursuit and resumes displaying.

Mating. Acceptance of the male and mounting are preceded by the female extending her ovipositor aculeus while still in labellar contact with the male. The male immediately breaks away and moves behind her. The male becomes very slow and deliberate in his movements, a distinct behavioral change from that of an aggressor, and waits behind the female, occasionally touching his foretarsi to the apices of her wings. When ready for copulation, the female drops her wings to her sides, exposes her abdomen, and extends her ovipositor its full length. The male immediately mounts her dorsally and touches his terminalia to the aculeus tip. The fully extended ovipositor is so long that the male rides atop the ovipositor as the female moves about. After 1-2 min, the female slowly retracts her ovipositor as the male moves up onto her abdomen. He remains with his foretarsi around the broadest portion of her abdomen near the junction of the thorax, his middle tarsi strokes the sides of her abdomen, and his hind tarsi touches the substrate. Couples walked to adaxial surfaces of leaves near stems in shade and remained in copula from 2.5 to $4 \mathrm{~h}(n=4)$.

Mating in $P$. gentilis in the field began from 1000 to 1100 hours; however, laboratory matings began in the afternoon. Other tephritids are reported to mate late in the afternoon and on the 


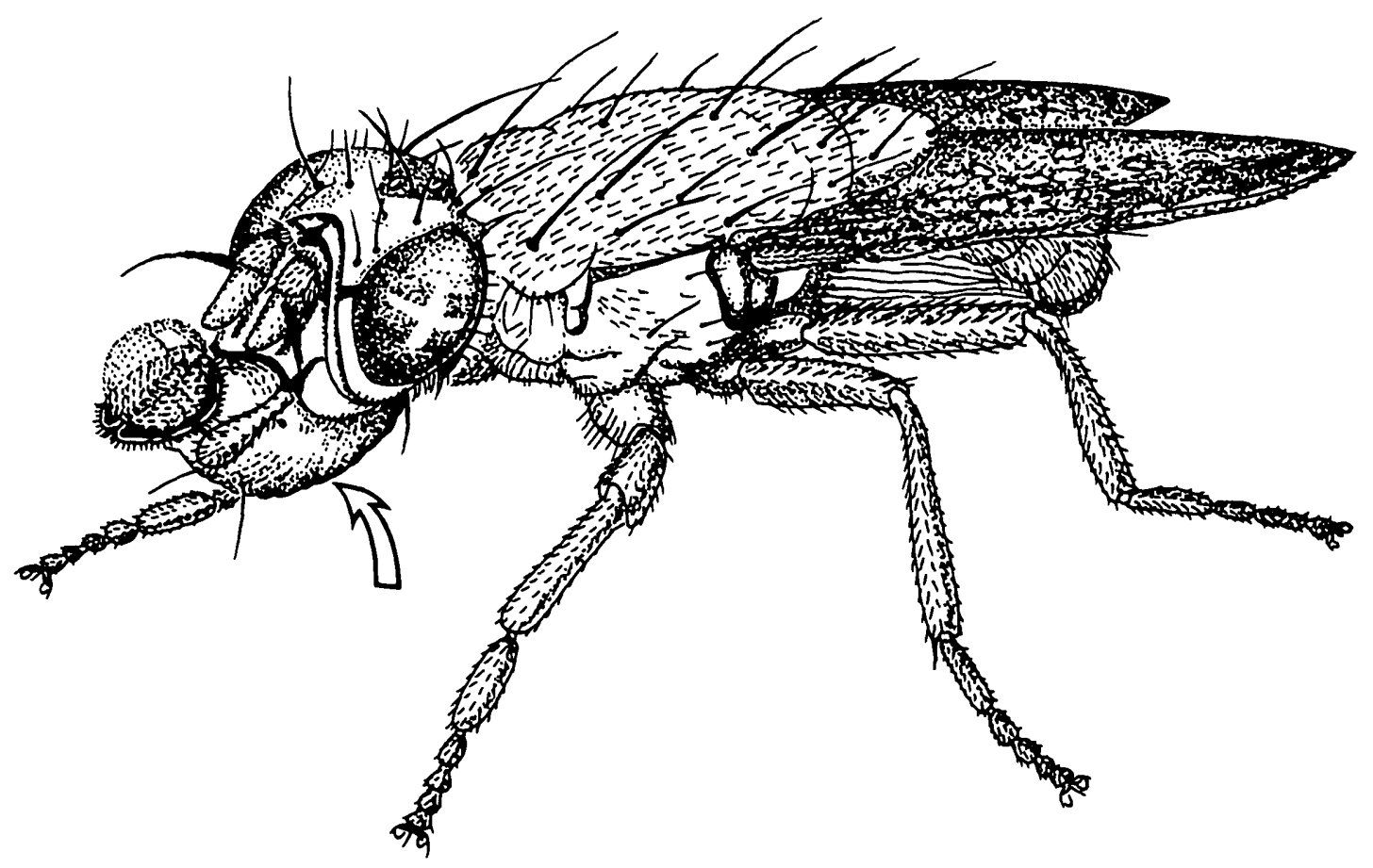

Fig. 5. Male courtship display. Arrow points to extended ventral head capsule membrane.

undersides of leaves (Bateman 1972, Batra 1979, Freidberg 1981, Polloni \& da Silva 1986). Morgante et al. (1983) reported early morning mating by Anastrepha fraterculus (Wiedemann). Cavender \& Goeden (1983) used times of mating to help distinguish two closely related species of Trupanea.

Oviposition. A female examines and selects an immature capitulum for oviposition by probing its center with her ovipositor. She places the tip of her ovipositor on the capitulum surface, with or without first touching her extended mouthparts to the capitulum for less than $3 \mathrm{~s}$. She bends her abdomen down and beneath her so that it is anticlinal to the long axis of her body and thrusts the tip of her ovipositor into the central opening between the apices of the bracts. She stands horizontally, faces away from the center of the capitulum with her wings flat over her dorsum and slightly parted. The ovipositor is pushed deeply into the capitulum with short up-and-down movements to probe or deposit eggs. Females face in different directions during each probe with no discernible pattern. The outermost one or two layers of bracts are usually punctured so the female can reach a suitable oviposition site.

A parasagittal section of the female ovipositor is illustrated in Fig. 6. When extended for egg deposition, the eversible membrane unrolls by hydrostatic pressure from the apex of the syntergosternite (terminology after Norrbom \& Kim 1988).
The aculeus is pushed outward until the common oviduct is completely extended from its normally folded position.

Oviposition was observed and timed in the field. A single act of oviposition was defined as the total time from the first probe with the ovipositor to egg deposition. The longest probe duration was made when egg deposition occurred, usually at or near the end of the oviposition episode. The longest probe was sometimes followed by a few short probes with the ovipositor, also counted in the total oviposition time. Thus, the total time spent ovipositing averaged $10 \pm 2.0(n=18$; range, $1.5-30) \mathrm{min}$. The total number of probes by a single female on a single capitulum while ovipositing averaged $9 \pm$ $2(n=18$; range, $1-34)$. The average time of a single probe (excluding egg deposition) was $10 \pm$ $2(n=30$; range, $1-35)$ s. The average egg deposition time, defined as the probe of longest duration while ovipositing, lasted $5.5 \pm 2$ ( $n=9$; range 1.520) $\mathrm{min}$.

After eggs are laid, the female removes her ovipositor from the capitulum and begins to groom. The hind tibiae are rubbed down the lateral aspect of syntergosternite 7 and the partially exerted aculeus, then onto the surface of the capitulum.

Natural Enemies. Pteromalus coloradensis (Ashmead) was the only parasite reared from $P$. gentilis. Percentage parasitization by $P$. coloradensis, a solitary, larval-pupal parasite, was $13 \%$ 


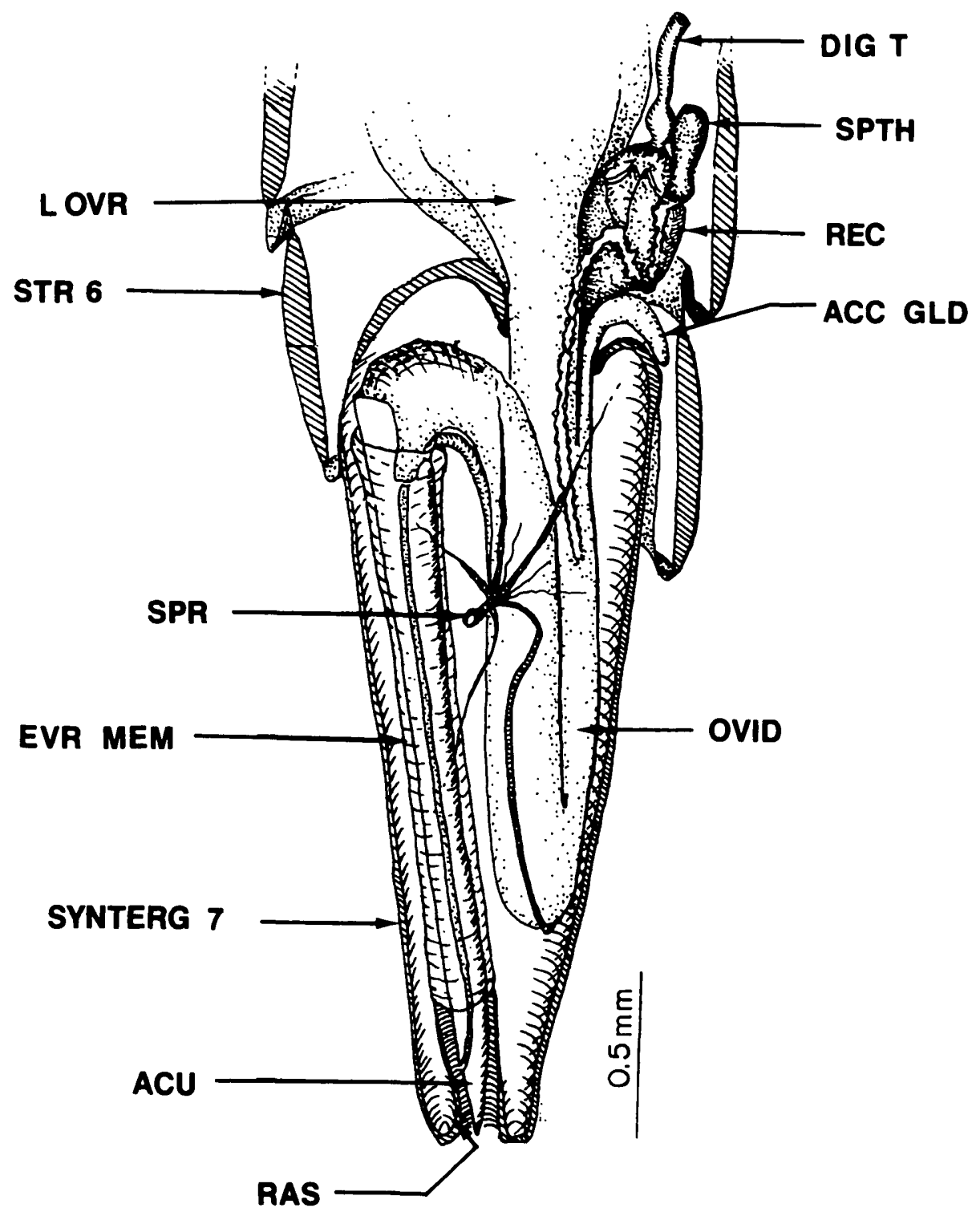

Fig. 6. Parasagittal view of female ovipositor with left spiracle and tracheae in place. ACC GLD, accessory gland; ACU, aculeus; DIG T, digestive tract; EVR MEM, eversible membrane; L OVR, left ovary; OVID, oviduct; RAS, rasper; REC, rectum; SPTH, spermathaeca; SPR, spiracle; STR 6, sternum 6; SYNTERG 7, syntergosternite 7 .

(Headrick \& Goeden 1989). Adult mortality also was attributed to spiders in the families Thomasidae and Salticidae.

\section{Acknowledgment}

We thank T. S. Bellows, G. Gordh, M. S. Moratorio, and D. W. Ricker for technical assistance; T. C. Baker, F. L. Blanc, and J. A. McMurtry for helpful comments on early drafts of the manuscript; and two anonymous reviewers for their thorough and helpful reviews.

\section{References Cited}

Bateman, M. A. 1972. The ecology of fruit flies. Annu. Rev. Entomol. 17: 493-518.

Batra, S. W. T. 1979. Reproductive behavior of $E u$ aresta bella and E. festiva (Diptera: Tephritidae), potential agents for the biological control of adventive North American ragweeds (Ambrosia spp.) in Eurasia. N.Y. Entomol. Soc. 87: 118-125.

Berube, D. E. 1978. Larval descriptions and biology of Tephritis dilacerata (Diptera: Tephritidae), a can- 
didate for the biocontrol of Sonchus arvensis in Canada. Entomophaga 23: 69-82.

Burk, T. 1983. Behavioral ecology of mating in the Caribbean fruit fly, Anastrepha suspensa (Loew) (Diptera: Tephritidae). Fla. Entomol. 66: 330-344.

Cavender, G. L. \& R. D. Goeden. 1982. Life history of Trupanea bisetosa (Diptera: Tephritidae) on wild sunflower in southern California. Ann. Entomol. Soc. Am. 75: 400-406.

1983. On distinguishing Trupanea bisetosa (Coquillett) from $T$. nigricornis (Coquillett) (Diptera: Tephritidae). Proc. Entomol. Soc. Wash. 85: 275-281.

1984. The life history of Paracantha cultaris (Coquillett) on wild sunflower, Helianthus annuus $\mathrm{L}$. ssp. lenticularis (Douglas) Cockerell, in southern California (Diptera: Tephritidae). Pan-Pac. Entomol. 60: 213-218.

Christenson, L. D. \& R. H. Foote. 1960. Biology of fruit flies. Annu. Rev. Entomol. 5: 171-193.

da Silva, M. T., Y. J. Polloni \& S. Bressan. 1985. Mating behavior of some fruit flies of the genus Anastrepha Schiner, 1868 (Diptera: Tephritidae) in the laboratory. Rev. Bras. Entomol. 29: 155-164.

Dodson, G. 1987. Biological observations on Aciurina trixa and Valentibulla dodsoni (Diptera: Tephritidae) in New Mexico. Ann. Entomol. Soc. Am. 80: 494-500.

Foote, R. H. \& F. L. Blanc. 1963. The fruit flies or Tephritidae of California. Bulletin of the California Insect Survey, vol. 7.

Freidberg, A. 1981. Mating behavior of Schistopterum moebiusi Becker (Diptera: Tephritidae). Isr. J. Entomol. 15: 89-95.

Goeden, R. D. 1987. Life history of Trupanea conjuncta (Adams) on Trixis californica Kellogg in southern (alifornia (Diptera: Tephritidae). Pan-Pac. Entomol. 63: 739-743.

1988. Life history of Trupanea imperfecta (Coquillett) on Bebbia juncea (Bentham) Greene in the Colorado desert of southern California (Diptera: Tephritidae). Pan-Pac. Entomol. 64: 345-351.

Goeden, R. D. \& D. W. Ricker. 1986a. Phytophagous insect faunas of two introduced Cirsium thistles, $C$. ochrocentrum and C. vulgare, in southern California. Ann. Entomol. Soc. Am. 79: 945-952.

1986b. Phytophagous insect faunas of the two most common native Cirsium thistles, C. californicum, and C. proteanum, in southern California. Ann. Entomol. Soc. Am. 79: 953-962.

$1987 \mathrm{a}$. Phytophagous insect faunas of the native thistles, Cirsium brevistylum, Cirsium congdonii, Cirsium occidentale, and Cirsium tioganum, in southern California. Ann. Entomol. Soc. Am. 80: 152-160.

1987b. Phytophagous insect faunas of native Cirsium thistles, C. mohavense, C. neomexicanum, and $C$. nidulum, in the Mojave Desert of southern California. Ann. Entomol. Soc. Am. 80: 161-175.

Goeden, R. D., T. D. Cadatal \& G. L. Cavender. 1987. Life history of Neotephritis finalis (Loew) on native Asteraceae in southern California (Diptera: Tephritidae). Proc. Entomol. Soc. Wash. 89: 552-558.

Headrick, D. H. \& R. D. Goeden. 1989. Life history of Pteromalus coloradensis (Hymenoptera: Pteromalidae) a parasite of Paracantha gentilis (Diptera: Tephritidae) in Cirsium thistle capitula. Proc. Entomol. Soc. Wash. 91: 594-603.
In press. Description of the immature stages of Paracantha gentilis (Diptera: Tephritidae). Ann. Entomol. Soc. Am.

Hering, E. M. 1940. Neue alt-und neuweltliche Bohrfliegen (Diptera: Tephritidae). Arb. Morphol. Taxon. Entomol. Berlin-Dahlem 7: 50-57.

Morgante, J. S., A. Malavasi \& R. J. Prokopy. 1983. Mating behavior of wild Anastrepha fraterculus (Diptera: Tephritidae) on a caged host tree. Fla. Entomol. 66: 234-241.

Munz, P. A. 1974. A flora of southern California. University of California Press, Berkeley.

Nation, J. L. 1972. Courtship behavior and evidence for a sex attractant in the male Caribbean fruit fly, Anastrepha suspensa. Ann. Entomol. Soc. Am. 65: 1364-1367.

Norrbom, A. L. \& K. C. Kim. 1988. Revision of the schausi group of Anastrepha Schiner (Diptera: Tephritidae), with a discussion of the terminology of the female terminalia in the Tephritoidea. Ann. Entomol. Soc. Am. 81: 164-173.

Pemberton, R. E., C. E. Turner \& S. S. Rosenthal. 1985. New host records for tephritid flies (Diptera) from Cirsium and Saussurea thistles (Asteraceae) in California. Proc. Entomol. Soc. Wash. 87: 790-794.

Piper, G. L. 1976. Bionomics of Euarestoides acutangulus (Diptera: Tephritidae). Ann. Entomol Soc. Am. 69: 381-386.

Polloni, Y. J. \& M. T. da Silva. 1986. Considerations on the reproductive behavior of Anastrepha pseudoparallela Loew 1873 (Diptera: Tephritidae). In A. P. Economopoulos [ed.], II International Symposium Fruit Flies/Crete.

Pritehard, G. 1967. Laboratory observations on the mating behavior of the island fruit fly Rioxa pornia (Diptera: Tephritidae). J. Aust. Entomol. Soc. 6: 127132.

Prokopy, R. J. \& G. L. Bush. 1973. Mating behavior of Rhagoletis pomonella (Diptera: Tephritidae). IV. Courtship. Can. Entomol. 105: 873-891.

Prokopy, R. J. \& J. Hendrichs. 1979. Mating behavior of Ceratitis capitata on a field-caged host tree. Ann. Entomol. Soc. Am. 72: 642-648.

Tauber, M. J. \& C. A. Toschi. 1965a. Life history and mating behavior of Tephritis stigmatica (Coquillett) (Diptera: Tephritidae). Pan-Pac. Entomol. 41: 73-79.

1965b. Bionomics of Euleia fratria (Loew) (Diptera: Tephritidae). I. Life history and mating behavior. Can. J. Zool. 43: 369-379.

Wangberg, J. K. 1978. Biology of gall-formers of the genus Valentibulla (Diptera: Tephritidae) on rabbitbrush in Idaho. J. Kans. Entomol. Soc. 51: 472-583.

Webb, J. C., J. L. Sharp, D. L. Chambers, J. J. McDow \& J. C. Brenner. 1976. The analysis and identification of sounds produced by the male Caribbean fruit fly, Anastrepha suspensa (Loew) (Diptera: Tephritidae). Ann. Entomol. Soc. Am. 69: 415-420.

Zwölfer, H. 1974. Innerartliche Kommunicationssysteme bei Bohrfliegen. Biol. Unserer Zeit 4: 147-153.

Received for publication 7 June 1989; accepted 11 December 1989. 